\title{
Intellectual Property Management and Strategy in Business
}

\author{
Mirësi Çela, Phd Candidate \\ "A. Xhuvani" University, Faculty of Economy, Elbasan, Albania \\ e-mail: celamiresi@gmail.com \\ Lumnis Çela, Phd Candidate \\ "A. Xhuvani” University, Faculty of Human Sciences, Elbasan, Albania \\ e-mail: lumniscela@yahoo.com
}

\section{Doi:10.5901/mjss.2013.v4n11p445}

\section{Abstract}

Nowadays the way companies are managed has changed. The business strategy of the enterprises is formulated paying attention not only to the inner enviroment where it operates, but also to the outer one. Enterprises are using Intellectual Property (IP) as a principal activity for their economic growth. IP management is an important set of concepts, methods and proccesses created to fit IP of the firm with the defined objectives and business strategy. In the absence of a management system of IP, firms do not fully take advantage of their intellectual capital. Where is IP positioned in a company? Where is placed among other business assets? This paper aims on presenting a theoretical overview on Intellectual Property management of the firm, focusing mainly on objectives, strategies, their implementation and impact on performance.

Keywords: Intellectual property, SMEs, management, strategy

\section{Introduction}

Th e need for IP management is a consequence of globalisation and the growth of the knowledge economy. Large-scale enterprises with worldwide operations have already adapted to changed realities and now small and medium-sized enterprises (SMEs) feel the need to capitalize on their IP assets. We describe the meaning of IP management for SMEs, identifying the specific service needs of such companies.

Large businesses have grasped the need for IP management, but SMEs are only beginning to do so. However, we still know very little about the importance companies place on IP as a component of business and corporate strategy.

\section{IP in the company amongst business assets}

Intellectual property as defined by WIPO (World Intellectual Property Organization) refers to creations of the mind: inventions, literary and artistic works, and symbols, names, images, and designs used in commerce .

Ip is a very important element of a business. Patents, trademarks, trade secrets etc are assets that increase the value of a business. These assets are a special category of business assets which are named intangibles.

But where do the intangible assets stand in an enterprise ? How is it related to IP? The intangible assets and IP can be understood only in the enterprise context, where they are created, used and produce the most of their value.

Every enterprise small or large is compounded by three basic elements: (Smith \& Parr, 2005)

1. monetary assets

2. tangible assets

3. intangible assets

Enterprising $=$ monetary assets + tangible assets + intangible assets 


\section{The source of intellectual property}

Davis and Harrison (2001) defined intellectual capital (IC) as "knowledge that can be converted to value". They also determined that IC has two main components: human capital (ideas we have in our heads) and intellectual assets (ideas that have been codified in some manner). Within intellectual assets, there is a subset of ideas that can be legally protected, called intellectual property (IP). (See Figure 1.)

Figure 1. The source of intellectual property

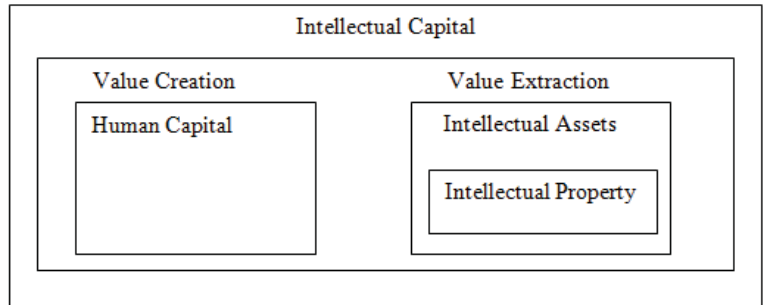

Intellectual Property are intellectual assets which are protected by law. The aim of management is "to produce" intellectual property.

\section{The Strategic objectives of intellectual property}

Companies with patent portfolios, create them with the expectations about the way they will be used in short term periods and in future technology based opportunities. The strategic objectives of intellectual property are: protection from competition, complementary protection, disputes avoidance, bases for alliances.

a. protection from competition; holding a patent gives the firm a monopolistic position in the market.

b. complementary protection; some patents develop not aiming the direct commercialization. The complementary patent groups formed around a key patent cope with a higher protection degree.

c. disputes avoidance; firms have the ability to commercialize their technologies for a long term without the threat of abuses with her IP rights.

d. bases for alliances; finding business partners is easier when the firm has a competitive patent portfolio.

\section{Intellectual property strategy}

The IP strategy reinforces the overall business strategy and will change as the business moves through different stages of its development. Also it differs from one market to another, because the business will be at different stages of it life cycle. Management of the company should be involved in drawing up the IP strategy and understands how it will support the business objectives. The key people to be engaged are the chief executive, finance director, tax advisor, general counsel, chief technology officer and chief operating officer.

The IP strategy should be reviewed whenever the business strategy changes and at least once a year.

\subsection{Components of an IP strategy}

- protection; registration of IP at the resposible institutions

- enforcement; the specific country procedures to be followed

- management of relationship and behaviour, an employement contract should contain express confidentiality clauses and provide for the ownership of IP developed by employees. Similar provisions should be in all contracts with business partners wether private or state. (SME Helpdesk, 2012)

A good IP management strategy ebhances the ability of the business to raise funding by managing the issues that affect valuations of IP assets. 


\subsection{Basic IP strategies}

There are a range of IP strategies for a company. Nevertheless, four basic IP strategies can act as a foundation for later refinements. (These correspond broadly to the levels of expectation described in the pyramid of IP management):

- A path to minimize risk: A key activity for those pursuing this strategy is portfolio building and cross-licensing to avoid litigation.

- A path to cost reduction: Virtually all companies follow a cost reduction strategy. They look to maintain the effectiveness of their IP protection program while cutting the cost of doing so.

- A path to value. The companies seek to profit from direct use of the IP itself, rather than only through the products and services protected by the IP.

- A path to strategic value: The focus is on utilizing IP to change the nature or direction of competition, relying on strategic patenting, refocusing R\&D and rethinking partnerships with customers, suppliers, or any other relevant parties. (Sullivan \& Harrison, 2008)

Selecting an appropriate IP strategy a company must take into account all the elements that may impact on its commercialization and balance the pros and cons before a decision is made as to what strategy to adopt to maximize the benefits for the company from IP assets. As well as considering the strengths and weaknesses of each strategy the company's own driving forces to expand road and the target country's condition for the commercialization and timing for such an expansion, should particularly pay attention to the IP competence of the company. (Yang, 2008)

\subsection{The value hierarchy of IP management}

Davis and Harrison in their work (2001) have structured the Value Hierarchy, which is a pyramid with five levels. Each level represents a different expectation that the company has about the contribution that its IP function should be making to the corporate goals. Like building blocks, each higher level relies on the foundation of the lower levels and contributes to the shareholder value.

Figure 2. The value hierarchy of Ip management

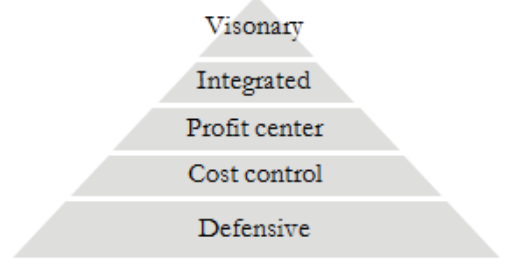

\subsubsection{Defensive level.}

When a corporation owns an intellectual asset, it can prevent competitors from using the asset. At this level companies use their IP for defensive purposes only and view IP as a legal asset. Their goals are to protect their own innovations, to ensure that they don't infringe the IP of others. The costs in filing fees, enforcement and other legal expenses can be high.

\subsubsection{Cost control level}

Companies at this level still have a defensive approach, but now focus on finding ways to obtain protection while simultaneously reducing the costs of creating and maintaining their IP portfolios.

\subsubsection{Profit center level}

Companies at this level turn their attention to more proactive strategies that can generate a great amount of additional revenues while further continuing to trim costs. Passing from the previous levels of activity to this one requires a major 
change in a company's attitude-and even its organization. In such a company, IP may have its own function. It is at this level that companies begin to view IP as a business asset, rather than just a legal asset.

\subsubsection{Integrated level.}

In this level the IP function serves to the organization as a whole. Here the company's business units have grasped the power of using IP for a range of business roles. IP use for business becomes integrated across all of the company's business activity.

\subsubsection{Visionary.}

At this level of IP management sophistication, companies take a long-term view of the company's role in business and in its industry. They seek to use the company's IP to create more strategic value.

It should not be inferred from this pyramid that the highest level of sophistication equates to the "best" level of IP management. What matters is to determine which level best suits the needs and capacity of your particular company. Every company can improve their position in the pyramid, so increasing shareholders value by strengthening their intangible assets. Each level serves as u building block for levels above it.

\section{Intellectual property administration and intellectual property management}

IP management is an important set of concepts, methods and proccesses created to fit intellectual property (IP) of the firm with the defined objectives and business strategy

Figure3 : The differences between IP administration and IP management

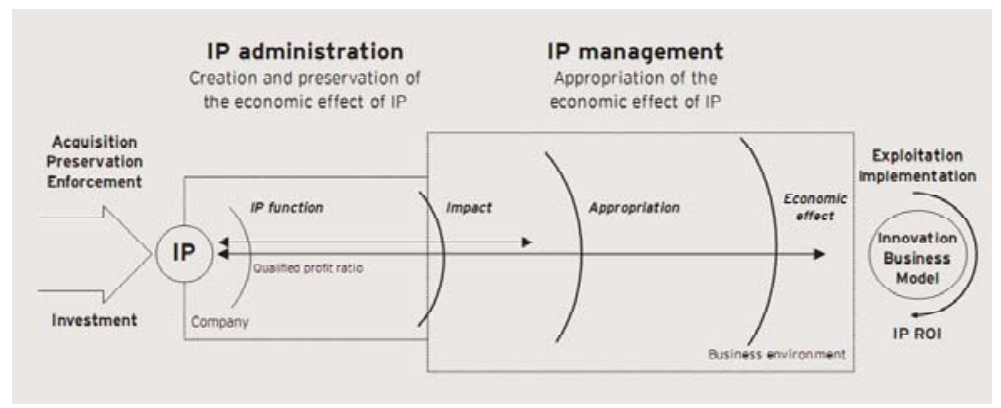

Source: Wurzer and DiGiammarino (2009).

Today large-scale enterprises accept IP as an asset, in the past only the legal aspects had played an important role. IP administration and IP management are often confused but they differ from each other.

While IP administration mainly deals with the IP asset itself (the acquisition, preservation and all legal aspects), the central task of IP management is the integration of IP into innovation strategies and business models. To put it simply, IP administration strives to enable the usage of the legal and economic functions of IP:

○ the protection of an invention (patents, to exclusively identify and protect the commercial source of a product or service (trade marks)

○ to block competition (IP rights)

$\circ$ and to enable inventory stocks, licences etc.

Those functions may have an economic effect. For example, they prevent a competitor from offering similar functionality in its products. It is the task and responsibility of IP managers to appropriate those functions and the economic consequences for the benefit of the company; in other words to make sure that the company actually can cash in on IP and its effects. As a rule, the economic benefit for the company is a cash flow (of some sort). Therefore, the target figures for IP management are key operational figures such as rate of return, profitability and turnover. (Wurzer \& DiGiammarino, 2009) 
6.1 The IP management can be divided into three activity clusters:

1. Innovation support,

2. Portfolio management and

3. IP exploitation.

\subsection{The performance framework of IP system}

There are three components that together fashion an IP system that fosters productivity and ensures equitable outcomes for industrv and consumers:

1. the instruments of IP, namely patents, copyright, designs, trade marks and sui generis rights, ought to be balanced, coherent and flexible:

2. the operations, i.e. the award, use and enforcement of those IP rights, must be efficiently administered; and

3. the national and international organisations responsible for the governance of policy and operations must be clear and well run. (Gowers, 2006)

\section{SMEs and IP management}

\subsection{Small and Medium Enterprises and the IP system}

According to United Nations (2011), SMEs underutilize the formal IP system because of two main reasons: firstly the high costs of protection and enforcement; and, secondly, the lack of awareness by SMEs on how the IPR system works.

\subsubsection{Costs}

The costs related to protection and enforcement of IPRs, particularly patents, are considered by SMEs as a great barrier to the use of the formal IP system. In their budgeting, besides the costs related to the acquisition of the registered IPRs also need to be considered costs related to the preparation of the applications and possibly translation expenses.

These costs are perceived by many SMEs as by far exceeding the prospective benefits that derive from protection, especially when considering that most of these costs are incurred before the products reach the markets and thus before the realization of any income or profits.

\subsubsection{Lack of awareness}

SMEs do not make sufficient use of the formal IP system because they lack good quality advice. Small businesses are not aware of the benefits and the financial and strategic value of IP, and that in general, innovators and creators are not aware of most or all the categories of IP and of the benefits associated with each type of IP protection.

Wurzer and DiGiammarino (2009) identifiy a number of typical differences between SMEs and MNCs ( multinational corporations):

- Resources; SMEs have limited resources

- Market access; SMEs have restricted distribution channels and fewer capacities for marketing and advertisement.

- Complexity; MNCs find easily partners for cooperation, SMEs depend on service providers.

- Decision- making qualities: SMEs are advantageous because they make quick decisions.

\subsection{How can Intellectual property enhance the market value of SMEs?}

The value of intellectual property (IP) is often not adequately appreciated and its potential for providing opportunities for future profit is widely underestimated by SMEs. IP can become a valuable business asset. (WIPO, n.d.)

- IP may generate an income for SME through the licensing, sale, or commercialization of the IP-protected products or services that may significantly improve an enterprise's market share or raise its profit margins.

- IP rights can enhance the value or worth of SME in the eyes of investors and financing institutions.

- In the event of a sale, merger or acquisition. IP assets may significantly raise the value of the enterprise, and 
at times may be the primary or only true assets of value.

The strategic utilization of IP assets can, therefore. substantially enhance the competitiveness of SMEs, which should make sure that they are ready to face the challenge and take measures to exploit their IP and protect it wherever possible.

\section{Conclusions}

The enterprise to gain profits by IP should manage it well. It should build the IP strategy as part of its business strategy, it should have an IP portfolio and build a functional IP management system in the enterprise.

There is always demand for legally protected products or services in the business arena and enterprises should always take care of protection, management and enforcement of products /services, than IP becomes a valuable asset. Intellectual Property may generate incomes and improve market's share, enhances the value in the eyes of financing institutions and investors for SMEs.

The strategic utilization of IP assets can, therefore. substantially enhance the competitiveness of SMEs. IP Offices and SME support institutions, should consider, awareness raising and training in IP, as one the main activities identified at the national level to facilitate a wider and more effective use of the formal IP system by SMEs.

\section{References}

Davis, J., and Harrison, S. (2001), Edison in the board room: How leading companies realize value from their intellectual assets, John Wiley and Sons, New York, pp 1-36.

Gowers Review (2006), HM Treasury, London: Crown, pp.35 Retrieved January,15, 2013 from http://www.hm-treasury.gov.uk/d/ pbr06_gowers report_755.pdf

SMEs, Helpdesk,(2012) Managing IP as a business Asset. Retrieved November 20, 2012 from www.europa.eu.

Sullivan, P. and Harrison, S.(2008), WIPO Magazine. Retrieved June, 1,2013 from website http://www.wipo.int/wipo_magazine/en/ 2008/01/article_0008.html

Parr, R., and Smith, G. (2005), Intellectual Property: Valuation, Exploitation, and Infringement Damages, income approach - quantifying the economic benefit, John Wiley and Sons, Inc. pp. 206

United Nations Economic Commission for Europe (2011), Intellectual Property Commercialization, Policy options and practical instruments, New York and Geneva, pp.66 Retrieved November, 20, 2012 from http://www.unece.org/fileadmin/DAM /ceci/publications/ip.pdf

WIPO, Small and Medium -sized Enterprises Division, Intellectual property for business.(n.d.) Retrieved May,12, 2013 from http:/www.wipo.int/sme

Wurzer , J. A., DiGiammarino P.(2009) IP management: SMEs, Smaller IP owners seek better management and returns. Retrieved on May, 10, 2013 from http://anaqua.com/community/IP_Management_for\%20_SMEs.pdf

Yang, D. (2008), Understanding and Profiting from Intellectual Property; $\bar{A}$ guide for Practitioners and Analysts, Palgrave Macmillan, New York, pp.207 